\title{
INVESTIGATIONS ON EFFECT OF CFRP STRIPS RETROFITTED USING NSM METHOD ON TWO-WAY NSC AND HSC SLABS SUBJECTED TO CONCENTRATED LOAD
}

\author{
Nandeesh M S ${ }^{1}$, Arjun R P Reddy ${ }^{2}$, Prabhakara $^{3}$ \\ ${ }^{1}$ M.Tech Student in Civil Engineering Department MSRIT, Bangalore \\ ${ }^{2}$ M.Tech Student in Civil Engineering, Department MSRIT, Bangalore \\ ${ }^{3}$ Professor and Head of the Department of Civil Engineering, MSRIT, Bangalore
}

\begin{abstract}
Experimental investigation on the effect of strengthening by NSM method using CFRP strips was conducted on simply supported two-way slabs. A total eight slabs, four control slabs and four NSM strengthened slabs, with an effective span of over 940mm and an effective depth of $74 \mathrm{~mm}$ were tested under a single point loading. Parameters varied in the study was the grade of concrete and reinforcement percentages. The performance of these specimen under the changing parameters were studied on the first crack load, ultimate load and on their corresponding deflections. Further the effect of NSM strengthening on all these parameters was also studied. The combined load deflection behaviour of slabs was plotted to understand the slab behaviour and the relevant conclusions were presented.
\end{abstract}

Keywords: Two-Way Slabs, NSM, Strengthening, Retrofitting, NSC, HSC.

\section{INTRODUCTION}

Concrete has become a widely used construction material due to its versatility, ease of preparation, applicability, durability and serviceability. Slabs are two-dimensional elements which rests on beams and columns in a structure. Slabs form the most important part of any structure which provide the most useful area for working in the structure.

HSC are gaining wide popularity in the present day field applications due to its advantages like early strength gain, better durability, impact and toughness characteristics. HSC are seen to exhibit better durability and corrosion resistance in comparison to Normal Strength Concrete (NSC). HSC provides higher strength per unit cost, per unit weight and per unit volume thus can lead to reduced size and weight of structures, increases stability and reduces deflections. The mechanism of crack formation and propagation, deformation etc., depend on the mechanical properties of concrete and thus changes from NSC to HSC.

Slabs which have undergone deformity or have been rendered insufficient to perform under a given loads need to be repaired and being the most important structural component it is not easy to be removed and recast as it is very difficult, hinders the operational capacity of the structure during such reconstruction. The concept of strengthening the slabs is a suitable solution to such problem. Of all the available retrofitting procedures the most preferred one under high strain rate conditions is retrofitting using Fibre reinforced polymers (FRP). The methods widely used for retrofitting using FRP are External bonding (EB) and Near surface mounting (NSM). NSM technique is the strengthening system which involves provision of additional reinforcement in form of bars or strips in the groove made in concrete cover. The use of Near-Surface Mounted (NSM) Fibre-Reinforced Polymer (FRP) is the latest method for increasing both flexural and shear strength of deficient Reinforced Concrete (RC) beams and slabs.

\section{LITERATURE REVIEW}

SUDARSANA RAO HUNCHATE et.al, [1]The authors have carried out investigations to give design mix for HPC by using silica fume and superplasticizers. Total six mixes were prepared by keeping w/c ratio 0.29 constant, varying silica fume percentage from which cubes and cylinders were casted. As the replacement increases the compressive strength increases up to optimum percentage and then decreases gradually.BANTHIA et.al, [2] They have reported the general bending load versus load point deflection graphs were plotted for various specimens for both static and dynamic loading. The higher values of fracture energies obtained from the composites than the unreinforced matrix. The conventionally reinforced concrete with its strategically placed reinforcing bars was found to be most impact resistant of other concretes such as normal strength plain concrete, High strength concrete, normal strength polypropylene fibre reinforced concrete and normal strength steel fibre reinforced concrete.RAKESH KUMAR SAHU et.al, [3]The present study was aimed to develop high strength concrete (HSC) mix design using locally available materials and Normal strength concrete (NSC) mix design. The functional formulas to determine the parameters for High strength concrete are obtained for water cement ratio, water content, FA content, $\mathrm{CA}$ content and cement 
content. Those equations are used to develop the mix designs for M50, M60 and M70.RP et.al.[4], have given the mix design procedure of HSC using $20 \mathrm{~mm}$ downsize aggregate, without using silica fume and keeping the water cement ratio between 0.23 to 0.25 With these they have achieved concrete of strength up to $120 \mathrm{MPa}$. This method provides the best strength gain with least cement content.

MICAEL INACIO, et.al, [4]An experimental research was conducted to investigate the punching behaviour of high strength concrete (HSC) flat slabs, presenting a compressive concrete strength of $130 \mathrm{MPa}$. All specimens exhibited a decrease of stiffness when the flexure cracks start to form and develop. Furthermore, before cracking, the stiffness of the HSC specimens was slightly higher than of the NSC specimen. The test results also showed a displacements decrease at failure with the increase of the longitudinal reinforcement ratio, while stiffness increased slightly. From the results obtained, and for this set of tests, it is possible to conclude that the use of HSC instead of NSC led to an increase up to $43 \%$ of the punching capacity. The increase of reinforcement ratio from $0.94 \%$ to $1.48 \%$ led to an increase of punching capacity of 12\%. ANDREAS ANDRESSON [5]The load carrying capacity of concrete slabs subjected to concentrated loads are studied considering both static and impact loads. The slabs failed in one-way flexure. The concrete fallout was more in the slabs with rebar mesh than the slabs with SFRC. The residual strength after the impact was sufficient to carry the static load of impact test.

HUBERT WITKOWSKI et.al., [6] have presented the bond test results of CFRP strips to concrete with respect to variations of concrete strength, beam span, bond length and ratio of internal steel reinforcement. Bond behaviour is dependent on bond length, concrete strength, adhesive property, dimensions of groove, FRP type, location of FRP with respect to concrete edge and interaction between steel and FRP reinforcement. $\boldsymbol{E}$. BONALDO et.al., [7]This paper presents the study conducted to assess the efficiency of NSM strengthening to increase flexural resistance of RC Slabs Maximum load taken by strengthened slab was almost five times unstrengthened slab. Maximum strain recorded in CFRP was about $80 \%$ of its ultimate strain. Providing of $0.12 \%$ of CFRP laminates increased service loads by $54 \%$.

\section{OBJECTIVES}

- To obtain the workable mix proportions for NSC (Normal Strength Concrete) and HSC (High Strength Concrete) which satisfies strength criteria.

- To record the flexural behaviour of slabs under static loading.

- To record the change in static behaviour when slabs are strengthened with NSM technique

- To analyse the static test results over the influencing parameters such as cracking load, ductility index, Energy absorption and failure criteria and how they change with strengthening.

\section{MATERIALS AND MIX PROPORTIONS}

Characterisation of materials used in the present investigation has been carried out as per the standard procedure. The various materials used in the experimental work are Cement, fine aggregate, coarse aggregate, water, reinforcing steel and admixtures. Each of the material used in the experiment has been discussed in detail below.

- CEMENT - In the present work, Ordinary Portland Cement of 53 grade conforming to IS: $12269-2013$ has been used.

- FINE and COARSE AGGREGATES - The fine and coarse aggregates used was as per the specifications as per IS 383-1970.

- REINFORCING STEEL - The reinforcing steel was found to satisfy the specifications as per IS 1786: 2008.

- ADMIXTURE - The superplasticizer used in the present work is Master Glenium Sky 8233 which is commercially marketed by BASF Construction Chemicals (India) Private Limited is used for M70 concrete and Siri plast is used for M20 concrete.

- WATER - Potable water free from injurious salts for both mixing and curing is used as per IS 456:2000

- CFRP strips, sponsored by FOSROC CHEMICALS, Bangalore which is marketed under the name "Nitowrap CFP" was used in the present study for retrofitting both NSC and HSC slabs

- The epoxy used for bonding the CFRP to slab in the study was manufactured by FOSROC CHEMICALS(India) Pvt. Ltd., Bangalore marketed under the name Nitowrap 40

\subsection{Mix Design Procedure}

There are many methods of mix design available for the Normal Strength Concrete (NSC) such as New British Method, IS method, ACI method, British method, Fineness modulus method, Maximum Density method, Road note No.4 method and minimum voids method. All these methods give a channelized procedure for proportioning the basic ingredients of the NSC. However, there is no single and channelized procedure available for HSC since there are many methods by which, one can get proportioning of HSC.

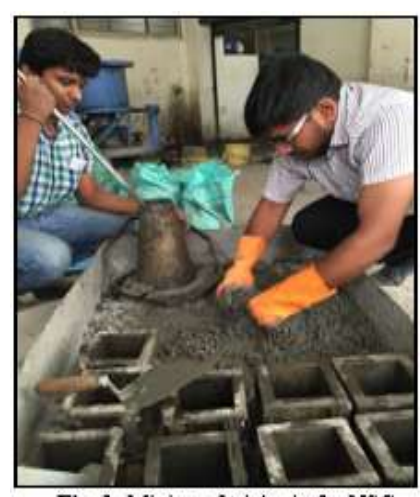

Fig. 1: Mixing of trial mix for NSC

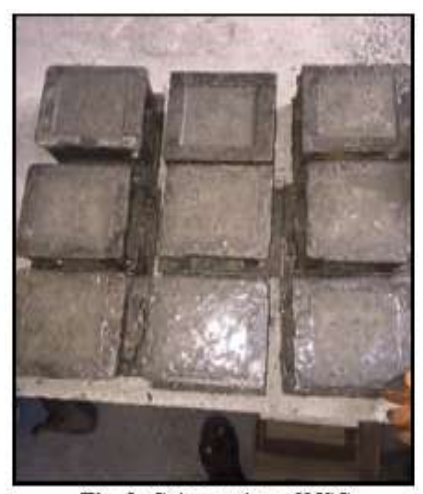

Fig. 2: Cube casting of NSC
Mix design procedure was formulated by combining the BIS method, ACI methods for concrete mix design and available literatures. This procedure was adopted as it gives the least 
cement requirement $\left(\mathrm{kg} / \mathrm{m}^{3}\right)$ for any particular mix compared to other methods. Also the charts and curves available Fig 1 shows the mixing of trial mix. Fig 2 shows the trial mixes which were cast into cubes.

\subsection{Trial Mixes}

NSC (M20) as per IS 10262:2009 and HSC (M70) as per $R$ P et.al Mix Design

Table 1: Trial Mix design specifications for NSC and HSC

\begin{tabular}{|l|l|l|}
\hline Ingredient & NSC & HSC \\
\hline Cement $\left(\mathrm{kg} / \mathrm{m}^{3)}\right.$ & 405.00 & 500 \\
\hline Coarse Aggregate $\left(\mathrm{kg} / \mathrm{m}^{3}\right)$ & 904.40 & 714 \\
\hline Fine Aggregate $\left(\mathrm{kg} / \mathrm{m}^{3}\right)$ & 801.33 & 1000 \\
\hline Water $\left(\mathrm{kg} / \mathrm{m}^{3}\right)$ & 202.50 & 150 \\
\hline Superplasticizer $\left(\mathrm{kg} / \mathrm{m}^{3}\right)$ & - nil- & 7.47 \\
\hline Compressive Strength $(\mathrm{MPa})$ & 25.51 & 76.02 \\
\hline
\end{tabular}

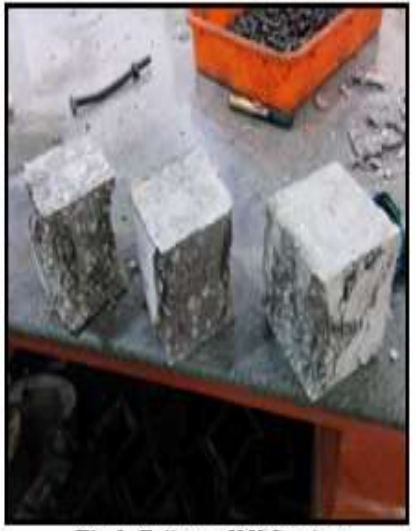

Fig.3: Failure of NSC cubes

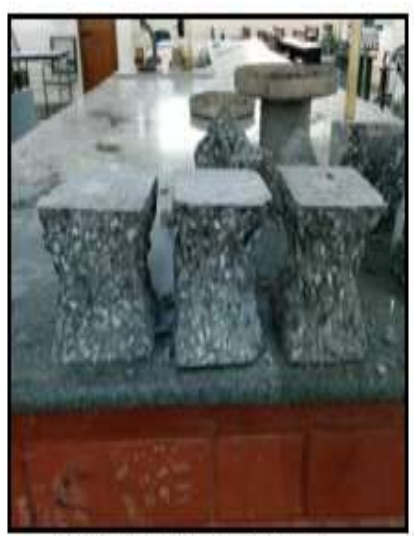

Fig,4: Failure of HSC cubes
Fig.3 shows the failure of NSC trial mix cubes under compression. Fig.4 shows the failure of HSC trial mix cubes under compression

\subsection{Specimen Casting}

The specimen casting was done to carry out the tests for studying the behaviour of slabs in static loading by varying the parameters such as grade of concrete, percentage of reinforcement and drop height. A total of 8 slabs were

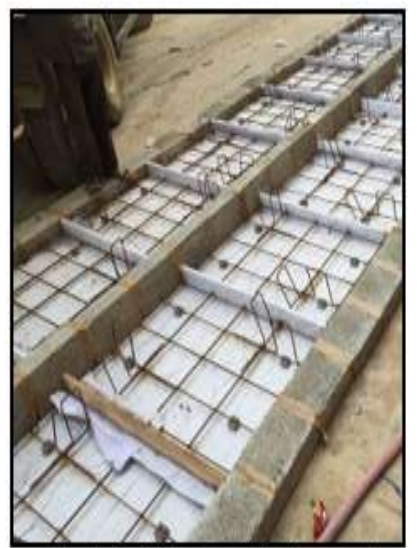

Fig.5: Reinforcement in the mould.

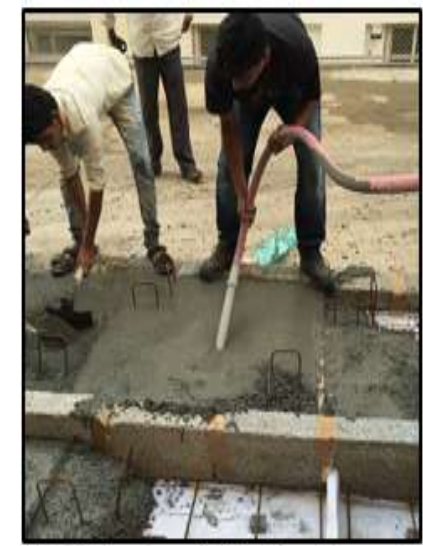

Fig.6: Pouring and vibrating of concrete required for all these parameters to be effectively studied.Fig.5 shows the typical reinforcement and mould used for casting. Fig 6 shows the pouring of concrete and vibrating it. The specimen naming was done in an efficient manner to identify the slabs with ease.NSM0 indicates control slabs with no strengthening and NSM1 indicates NSM strengthened slabs with $0.048 \%$ of reinforcement The table 2 provides the various slab identifications and the details of the specimen. Fig 7 shows the slump test being done on casting mix. Fig 8 shows the compaction factor test for NSC. Fig 10 shows the casting of cubes cylinders, prisms for casting mix. Fig 10 shows the finished test slabs.

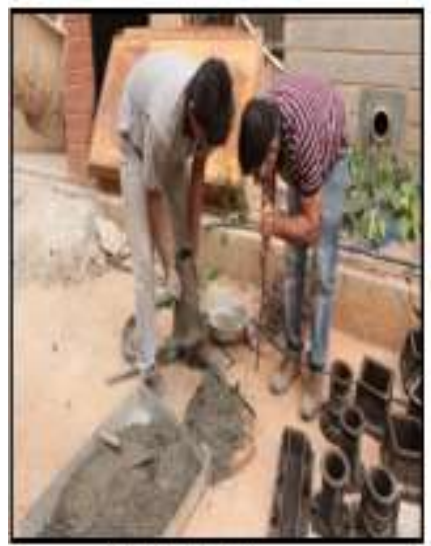

Figg: Sumpt test

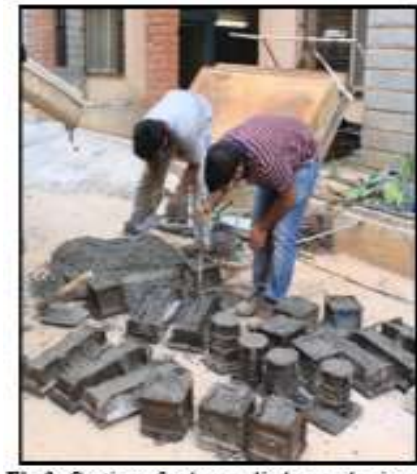

Fig. 9 : Casting of cubes, cylinders and prism

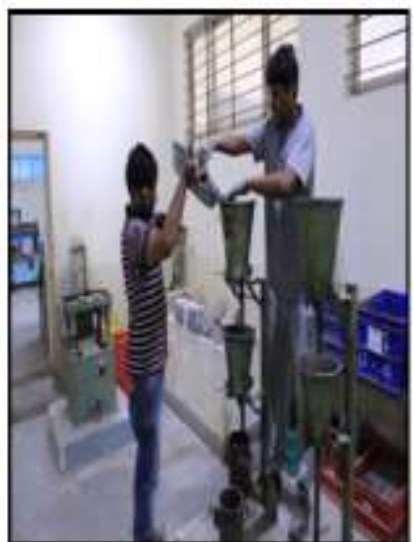

Fig.: Compection fator testing for NSC

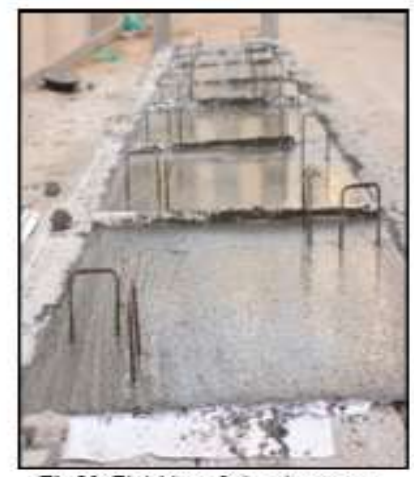

Fig.10: Finishing of placed concrete
Table 2: Specimen characterization and naming

\begin{tabular}{|c|c|c|c|c|}
\hline Sl $n$ & Slab $\mathbb{D}$ & Concrete Grade & \multicolumn{2}{|c|}{ Reinforcement details } \\
\hline 1 & MDOPTINSMO & \multirow{2}{*}{ MOO } & $\mathrm{PTI}=0.34 \%$ & $8 m m$ \& $240 \mathrm{CC}$ \\
\hline 2 & M20 PT2NSMO & & PT2 $=0.79 \%$ & $12 \mathrm{~mm} Q 240 \mathrm{CC}$ \\
\hline 3 & MOPTINSMO & \multirow{2}{*}{ Mo } & $\mathrm{PTI}=0.34 \%$ & $8 m m \& 240 \mathrm{CC}$ \\
\hline 4 & MOPT2NSMD & & PT2 $=0.39 \%$ & $12 \mathrm{~mm} \& 240 \mathrm{CC}$ \\
\hline 5 & M20 PT1NSMI & \multirow{2}{*}{ MDO } & $\mathrm{PTl}=0.34 \%$ & $8 \mathrm{~mm}$ \& $240 \mathrm{CC}$ \\
\hline 6 & M20PT2NSMI & & $P T 2=0.79 \%$ & $12 \mathrm{~mm} Q 2+0 \mathrm{CC}$ \\
\hline 7 & M70PTINSMI & \multirow{2}{*}{ M70 } & $\mathrm{PTI}=034 \%$ & $8 \mathrm{~mm} \& 240 \mathrm{CC}$ \\
\hline 8 & M70PT2NSMI & & $\mathrm{PT}=0.79 \%$ & $12 \mathrm{~mm} \quad \mathrm{Q} 240 \mathrm{CC}$ \\
\hline
\end{tabular}

\subsection{Strengthening of Slabs by NSM Technique}

The strengthening of slabs was carried out by NSM technique using CFRP strips. The strengthening was done in diagonal direction based of earlier researches. A zone of NSM strengthening marked by L/5.31 from the ends of the 
slab was identified for provision of NSM reinforcement. Fig 11 shows the CFRP laminates used in experiment. Fig 12 shows the groove cutting to apply epoxy and CFRP strips. Fig 13 shows a typical groove on the concrete surface. Fig 14 shows the typical groove layout. Fig 15 shows the placing of CFRP strips into epoxy filled groove. Fig 16 Surface finishing of NSM strengthened slab.

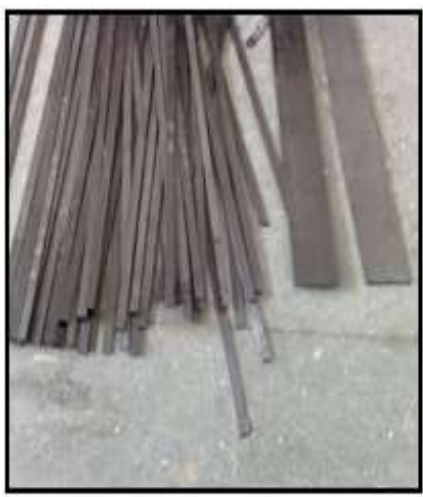

Fig 1l: CFRP Laminates cut into strip

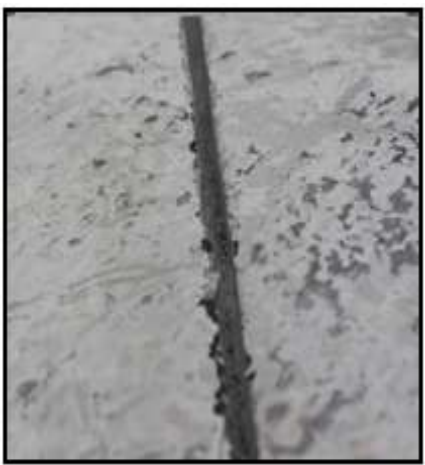

Fig 13: Typical Groove

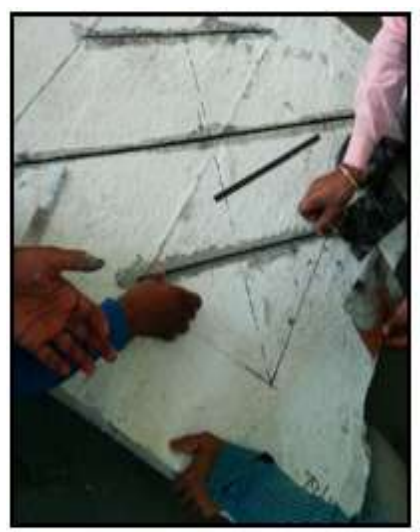

Fig 15: Placing of Strips

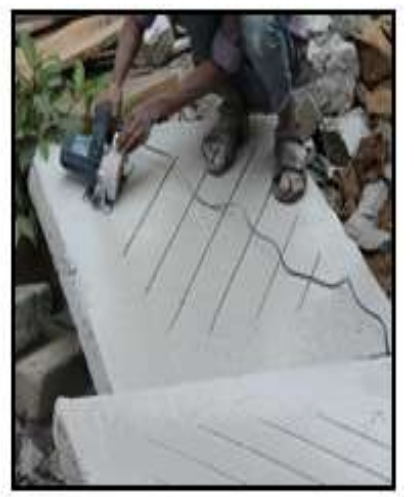

Fig 12: Groove Cutting

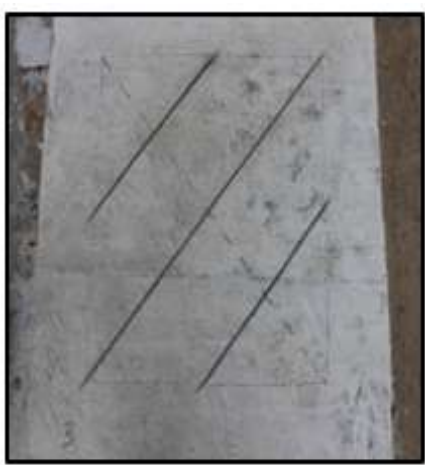

Fig 14: Typical Groove Layout

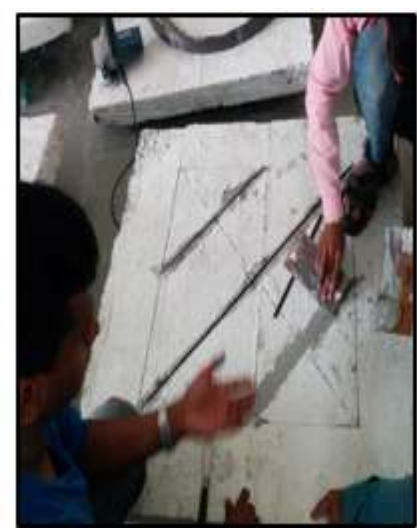

Fig 16: Surface finishing

\section{EXPERIMENTAL SETUP}

The static test setup was as shown in the figure17. The LVDT was used to measure the deflections and data acquisition system was used to capture the load deflection data. The rate of loading was $0.5 \mathrm{kN} / \mathrm{second}$.

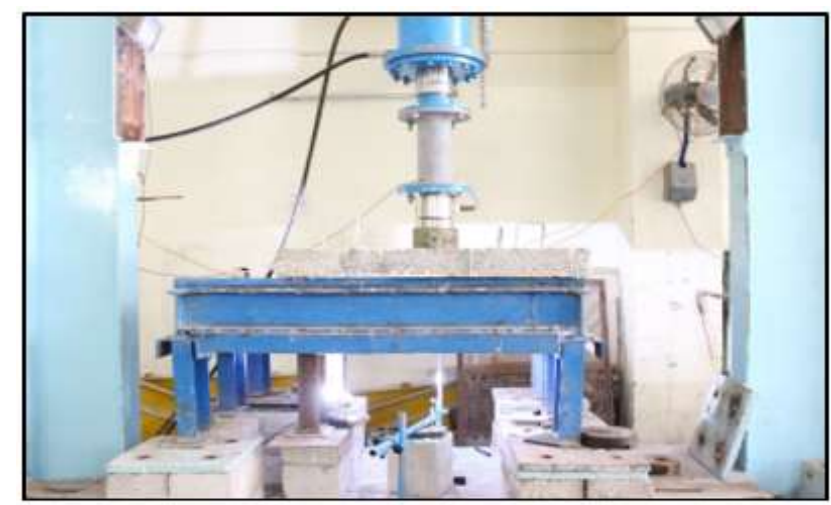

Fig.17: Test setup with specimen ready for testing

\section{RESULTS}

\subsection{First Crack Load and Ultimate Load}

From the experimental investigation conducted in the laboratory the first crack load and the ultimate load with their corresponding deflections were tabulated in the table 3.

Table 3: First crack Load and Ultimate Load with corresponding deflections

\begin{tabular}{|c|c|c|c|c|}
\hline SLAB ID & $\begin{array}{c}\mathbf{P c r} \\
(\mathbf{k N})\end{array}$ & $\begin{array}{c}\boldsymbol{\Delta}_{\mathbf{c r}} \\
(\mathbf{m m})\end{array}$ & $\mathbf{P u}(\mathbf{k N})$ & $\begin{array}{c}\boldsymbol{\Delta}_{\mathbf{u}} \\
(\mathbf{m m})\end{array}$ \\
\hline $\mathrm{M} 20 / \mathrm{PT} 1 / \mathrm{NSM} 0$ & 28.6 & 1.99 & 83.5 & 24.8 \\
\hline $\mathrm{M} 20 / \mathrm{PT} 2 / \mathrm{NSM} 0$ & 43 & 2.2 & 121.7 & 14.45 \\
\hline $\mathrm{M} 70 / \mathrm{PT} 1 / \mathrm{NSM} 0$ & 40.9 & 1.86 & 85.9 & 28.29 \\
\hline $\mathrm{M} 70 / \mathrm{PT} 2 / \mathrm{NSM} 0$ & 37 & 2.48 & 126.4 & 15.02 \\
\hline $\mathrm{M} 20 / \mathrm{PT} 1 / \mathrm{NSM} 1$ & 35 & 1.21 & 111.5 & 14.67 \\
\hline $\mathrm{M} 20 / \mathrm{PT} 2 / \mathrm{NSM} 1$ & 49 & 1.52 & 146.9 & 13.73 \\
\hline $\mathrm{M} 70 / \mathrm{PT} 1 / \mathrm{NSM} 1$ & 40.1 & 2.44 & 89.8 & 13.21 \\
\hline $\mathrm{M} 70 / \mathrm{PT} 2 / \mathrm{NSM} 1$ & 41.2 & 2.15 & 125.6 & 17.6 \\
\hline
\end{tabular}

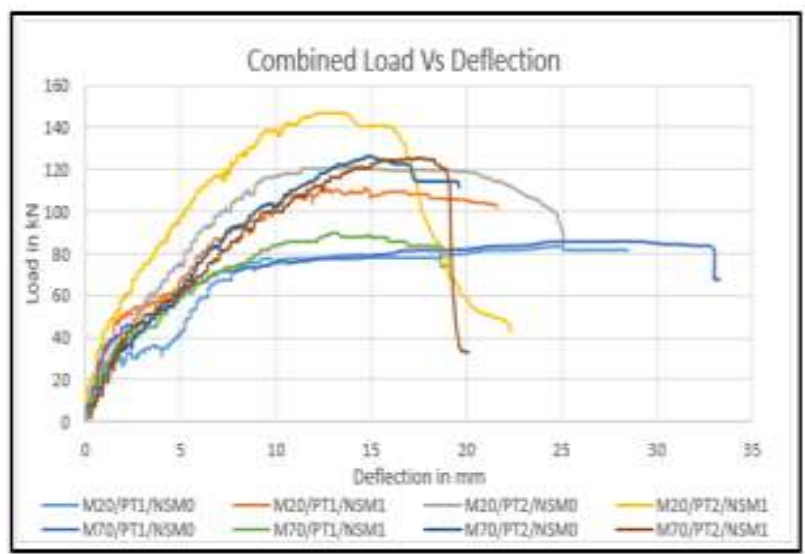

Fig. 18: Cembined Loas deflection curves of Test Specimen

From table 3, it was that the first crack load of control slabs of NSC slabs were increased by $50.35 \%$ and that of HSC slabs decreased by $10.54 \%$ when reinforcement ratio increased from $0.34 \%$ to $0.79 \%$. However, the ultimate load for NSC slabs increase by $45.75 \%$ and HSC slabs increased by $47.15 \%$ as the reinforcement increased from $0.34 \%$ to $0.79 \%$. In case of strengthened slabsfirst crack load NSC slabs were increased by $40 \%$ and that of HSC slabs 
increased by $2.74 \%$ when reinforcement ratio increased from $0.34 \%$ to $0.79 \%$. However, the ultimate load for strengthened NSC slabs increase by $31.75 \%$ and HSC slabs increased by $39.87 \%$ as the reinforcement increased from $0.34 \%$ to $0.79 \%$.

When comparing control slabs and strengthened slab it was observed that for NSC slab of $0.34 \%$ reinforcement ratio, the first crack load increased by $22.38 \%$ and ultimate load increased by $33.53 \%$. For NSC slab with $0.79 \%$ reinforcement ratio it was noticed that first crack load increased by $13.95 \%$ and ultimate load increased by $20.71 \%$. It was also observed that for HSC slabs with $0.34 \%$ reinforcement ratio first crack load reduced by $1.99 \%$ and ultimate load increased by $4.54 \%$ and for HSC slabs with $0.79 \%$ reinforcement the first crack load increased by $11.35 \%$ and ultimate load decreased by $0.64 \%$

In case of control slabs of $0.34 \%$ reinforcement the first crack load increased by $43 \%$ and for $0.79 \%$ reinforcement it decreased by $16.21 \%$ as the grade of concrete increased. However, for strengthened slabs of $0.34 \%$ reinforcement the first crack load increased by $14.57 \%$ and for $0.79 \%$ reinforcement it increased by $2.74 \%$ as the grade of concrete increased.

The deflection at first crack, for control slab of NSC was increased by $10.55 \%$ and for HSC it was increased by $33.3 \%$ with increase in reinforcement ratio from $0.34 \%$ to $0.79 \%$. The deflections at ultimate load, for NSC slabs reduced to $71.62 \%$ and for HSC slabs it reduced to $88.35 \%$ when reinforcement ratio increased from $0.34 \%$ to $0.79 \%$. In case of strengthened slab of NSC the deflection at first crack increased by $25.62 \%$ and for HSC slabs it decreased by $13.49 \%$ as the reinforcement ratio increased from $0.34 \%$ to $0.79 \%$. The deflections at ultimate load, for strengthened NSC slabs reduced by $6.84 \%$ and for HSC slabs it increased by $33.23 \%$ when reinforcement ratio increased from $0.34 \%$ to $0.79 \%$.

It was observed with control slabs that for $0.34 \%$ reinforcement ratio the deflection at first crack was reduced by $6.99 \%$ and for $0.79 \%$ reinforcement ratio it was seen to increase by $12.73 \%$ with increase in grade of concrete. The deflection at ultimate load of control slabs with $0.34 \%$ reinforcement ratio was seen to increase by $14.07 \%$ and for $0.79 \%$ reinforcement ratio it was seen to increase by $3.95 \%$. In case of strengthened slab, for $0.34 \%$ reinforcement ratio defection at first crack load increased by $101.65 \%$ and for $0.79 \%$ reinforcement ratio it increased by $41.45 \%$. The deflection at ultimate load of strengthened slab with $0.34 \%$ reinforcement was seen to reduce by $11.05 \%$ and for slab with $0.79 \%$ reinforcement it was seen to increase by $28.19 \%$. When comparing control slabs and strengthened slabs it was seen that for NSC slab with $0.34 \%$ reinforcement the deflection at first crack reduced by $64.46 \%$ and at ultimate load it reduced by $69.05 \%$ and with $0.79 \%$ reinforcement it was observed that the deflection at first crack load reduced by $44.74 \%$ and at ultimate load it reduced by $5.24 \%$. It was observed for HSC slab that with strengthening at reinforcement ratio $0.34 \%$ the deflection at first crack load increased by $31.18 \%$ and at ulimate load it was seen to reduce by $114.15 \%$ and for reinforcement ratio of $0.79 \%$ the deflection at first crack load was observed to reduce by $15.34 \%$ and at ultimate load it was seen to increase by $49.4 \%$.

\subsection{Load Deflection Behaviour}

The combined load deflection behaviour as shown in fig.6, it was observed for the control slabs that the maximum load was found to be more for higher percentage reinforcements regardless of the concrete grade. The deflections were found to be more in lower percentage of reinforcements. With strengthening it was observed that higher loads were reached at lesser deflections. This is because as the percentage of reinforcement increases, the stiffness of the member increases and provision of strengthening system was seen to further increase stiffness and hence the higher load capacity was observed. The strengthening system was seen to be most effective with NSC than HSC. This might be due to fact that the characteristic of epoxy and the HSC are not matching on micro level thus no distinct enhancement in strength is observed.

\section{CONCLUSION}

- As the reinforcement ratio increases the first crack load increases in case of control slab of NSC however it decreased in case of control slab of HSC.

- As the reinforcement ratio increases the ultimate load increases considerable in case of NSC but negligible in case of HSC slabs.

- Ultimate load increased noticeably only in case of NSC slabs upon strengthening. HSC slabs did not show any distinct increase in ultimate load capacity upon strengthening

- The deflections at first crack load was increased as the percentage of reinforcement was increased in case control slabs of both NSC and HSC

- The deflection of strengthened slabs at first crack load was seen to increase with increase in concrete grade for both reinforcement ratios.

- The deflection at ultimate load was seen to reduce for NSC and increase for HSC with increase in reinforcement ratio.

- All the slabs were failed in flexure except the control slab and strengthened slab of HSC with $0.79 \%$ reinforcement in which the punching shear failure was observed.

\section{REFERENCES}

[1].Sudarsana Rao Huchante, ShashidharChandupalle, Vaishali G Ghorpode and Venkata Reddy T C "Mix Design of High Performance Concrete Using Silica Fume and Superplasticizer" (March 2014) International Journal of Innovative Research in Science, Engineering and Technology (IJIRSET)Volume 3, Issue 3 
[2]. N Banthia, S Mindess, A. Bentur and M Pigeon (1988) "Impact Testing of Concrete Using Drop-weight Impact Machine" Experimental mechanics Pp 63-69

[3]. Rakesh Kumar Sahu, S P Mishra (March 2015) "Exploring possibility of Developing High Strength Concrete using Locally Available Materials", International Journal of Advanced Engineering Research and Studies" IV/II/76-78

[4].Prabhakara R, Muthu K U, Meenakshi R(2006),"Ultimate Flexural Strength of High Strength Concrete Beams", Indian Concrete Journal, Oct 2006, Pp 40-50

[5]. MicaelInacio, Antonio Ramos, Valter Lucio and Duarte Faria, "Punching of High Strength Concrete Flat SlabsExperimental Investigation" UNIC, Civil Engineering Department, Faculdade de Ciencias e Tecnologia, Universidade NOVA de Lisboa, 2859-516, Monte de Caparica, Portugal

[6]. Andreas Andersson, "Impact Loading on Concrete Slabs" (2014) Thesis submitted to KTH Architecture and Built Environment ISSN 1103-4289, Sweden

[7]. Hubert Witkowski\&Renata Kotynia, "Bond Between Nsm Reinforcement and Concrete", $8^{\text {th }}$ fib Ph.D. Symposium in Kgs, Lyngby, Denmark, June 20 - 232010

[8]. E. Bonaldo, JAO Barros, PB Lourenco, "Concrete Slabs Strips Reinforced with Epoxy Bonded Carbon Laminates into Slits", University of Minho, Portugal

[9]. IS 10262:2009, "Guidelines for Concrete Mix Design", BIS 